\title{
N-Myc-induced up-regulation of TRPM6/TRPM7 channels promotes neuroblastoma cell proliferation
}

\author{
Zheng Zhang ${ }^{1,3, *}$, Malika Faouzi ${ }^{1, *}$, Junhao Huang ${ }^{1}$, Dirk Geerts ${ }^{2}$, Haijie Yu ${ }^{1}$, Andrea \\ Fleig $^{1}$ and Reinhold Penner ${ }^{1}$ \\ ${ }^{1}$ Center for Biomedical Research, The Queen's Medical Center, University of Hawaii Cancer Center and John A. Burns School \\ of Medicine, University of Hawaii, Honolulu, U.S.A \\ ${ }^{2}$ Department of Pediatric Oncology/Hematology, Erasmus University Medical Center, Dr. Molewaterplein 50, GE Rotterdam, \\ the Netherlands \\ ${ }^{3}$ Department of Pharmacology, School of Pharmaceutical Sciences, Central South University, Changsha, Hunan, China \\ * These authors contributed equally to this work \\ Correspondence to: Reinhold Penner, email: rpenner@hawaii.edu \\ Andrea Fleig, email: afleig@hawaii.edu
}

Keywords: cancer/magnesium/neuroblastoma/N-Myc/TRPM6/TRPM7

Received: May 28, $2014 \quad$ Accepted: July 31, $2014 \quad$ Published: July 31, 2014

This is an open-access article distributed under the terms of the Creative Commons Attribution License, which permits unrestricted use, distribution, and reproduction in any medium, provided the original author and source are credited.

\section{ABSTRACT}

Intracellular levels of the divalent cations $\mathrm{Ca}^{2+}$ and $\mathrm{Mg}^{2+}$ are important regulators of cell cycle and proliferation. However, the precise mechanisms by which they are regulated in cancer remain incompletely understood. The channel kinases TRPM6 and TRPM7 are gatekeepers of human $\mathrm{Ca}^{2+} / \mathrm{Mg}^{2+}$ metabolism. Here, we investigated the human neuroblastoma cell line SHEP-21N in which the MYCN oncogene (encoding $\mathrm{N}-\mathrm{Myc}$ ) can be reversibly expressed under control of an inducible repressor. We report that $\mathrm{N}-\mathrm{Myc}$ expression increases cell growth and up-regulates both TRPM6 and TRPM7 expression. Membrane current analyses reveal that endogenous TRPM6/ TRPM7 currents exhibit reduced Mg-ATP suppression, increased $\mathbf{M g}^{2+}$ sensitivity, and diminished sensitivity to 2-APB inhibition. These properties are consistent with $\mathrm{N}$-Myc-induced increase of heteromeric TRPM7/TRPM6 channels promoting $\mathrm{Ca}^{2+}$ and $\mathrm{Mg}^{2+}$ uptake. Genetic suppression of TRPM6/TRPM7 through siRNA inhibits cell proliferation, suggesting that $\mathrm{N}$-Myc can promote neuroblastoma cell proliferation through up-regulation of divalent cation-transporting channels.

\section{INTRODUCTION}

Both $\mathrm{Ca}^{2+}$ and $\mathrm{Mg}^{2+}$ are critically involved in essentially every single step of cell proliferation, with cancerous cell growth representing a harmful form of deregulated proliferation. Interestingly, cancerous tissue acts as a $\mathrm{Mg}^{2+}$ trap at the expense of plasma or surrounding tissues, suggesting significant uptake by cancer cells [13]. The precise mechanisms by which divalent cations regulate cell proliferation remain to be elucidated, but recent evidence indicates critical involvement of the $\mathrm{Ca}^{2+}$ - and $\mathrm{Mg}^{2+}$-transporting transient receptor potential melastatin-related ion channels TRPM7 and TRPM6 [4-6]. TRPM7 and TRPM6 are channel kinases possessing both a $\mathrm{Ca}^{2+} / \mathrm{Mg}^{2+}$-permeable ion channel pore and a carboxyl- terminal atypical $\alpha$-kinase $[4,7,8]$. The two channels are highly analogous in many aspects, such as channel selectivity $[9,10]$, current-voltage relationship, as well as modulation by acidic $\mathrm{pH}[7,9,10]$, extracellular divalent cations $[9,10]$, and $\operatorname{PIP}_{2}[11,12]$. However, recently, they were shown to be differentially regulated by the channel blocker waixenicin A [13], 2-aminoethoxydiphenyl borate (2-APB) $[9,14]$, intracellular halides [15], as well as intracellular $\mathrm{Mg}^{2+}$ and ATP [14].

While TRPM7 is ubiquitously expressed and the native TRPM7-like current MagNuM ( $\mathrm{Mg}^{2+}$-nucleotideregulated metal ion current [7]) is measurable in virtually all cell types examined $[4,16]$, native currents of the more limitedly expressed TRPM6 have not yet been reported. TRPM7 channels are indispensable for $\mathrm{Mg}^{2+}$ 
homeostasis at both cellular and whole organism levels $[17,18]$. In contrast, TRPM6 is believed to be responsible for systemic $\mathrm{Mg}^{2+}$ regulation by mediating $\mathrm{Mg}^{2+}$ (re) absorption, as a mutation in the TRPM6 gene leads to an autosomal recessive form of familial hypomagnesemia with secondary hypocalcemia $[19,20]$. Consistent with its physiological function, TRPM6 expression appears to be relatively tissue-restricted, predominantly in the absorptive epithelia in the colon and kidney $[6,19,20]$. However, it is unknown whether TRPM6 is aberrantly expressed in other tissues or cells, possibly in a pathophysiological context.

Neuroblastoma, arising in tissues of the sympathetic nervous system such as sympathetic ganglia and the adrenal medulla, is the most common extracranial solid tumor of childhood and accounts for around $15 \%$ of all pediatric cancer deaths [21-23]. A factor that is strongly associated with advanced high-risk neuroblastoma and predicts poor outcome is amplification and concomitant high expression of MYCN [24,25], an oncogene encoding $\mathrm{N}-\mathrm{Myc}$, a nuclear phosphoprotein in the Myc family of helix-loop-helix transcription factors [26]. Enhanced expression of the oncoprotein N-Myc regulates a large number of genes, disrupting the cell cycle exit and terminal differentiation of neuroblasts and hence promoting neuroblastoma pathogenesis [27,28]. Given the role of $\mathrm{Mg}^{2+}$ in cell proliferation, the present study carefully examined two $\mathrm{Mg}^{2+}$-transporting channel kinases, TRPM7 and TRPM6, in neuroblastoma cells. Our results reveal that TRPM7 is essential for neuroblastoma proliferation and the additional expression of TRPM6 modulates the phenotype of native MagNuM currents, favoring divalent cation transport mediated by TRPM6 and TRPM7 and promoting neuroblastoma cell proliferation.

\section{RESULTS}

\section{N-Myc regulates expression of TRPM6 and TRPM7 in human SHEP-21N neuroblastoma}

We set out to examine the expression level of the $\mathrm{Mg}^{2+}$-influx channels TRPM6 and TRPM7 in the largest publicly available neuroblastoma expression profiling dataset, the Kocak-649 cohort [29]. On the basis of their MYCN gene copy number status, these tumor samples can be divided into MYCN-amplified $(n=93)$ or nonMYCN-amplified $(n=550)$ tumors. We first examined the expression level of N-Myc in these two groups and found that the expression level is, as expected, significantly higher in the MYCN-amplified samples $\left(p=1.5 \times 10^{-}\right.$ ${ }^{51}$, Fig. 1A). Interestingly, TRPM7 mRNA expression was found in all tumor samples, and was significantly correlated with both MYCN amplification $(p=2.3 \mathrm{x}$ $10^{-7}$, Fig. 1B) and mRNA expression $\left(p=3.5 \times 10^{-3}\right.$ in a $2 \log$ Pearson test). No significant correlations were found for TRPM6 (Fig. 1C), most likely due to the small numbers of tumors with significant TRPM6 expression (average TRPM6 expression was 8-times lower than that of TRPM7). In order to investigate the role of N-Myc in TRPM7/TRPM6 regulation, we chose the SHEP-21N cell line, a clone derived from the SHEP-2 neuroblastoma, in which N-Myc is constitutively expressed but can be experimentally repressed [30]. These cells contain a MYCN trans-gene under the control of a tetracyclineresponsive repressor element, so that tetracycline exposure turns off N-Myc expression. Quantitative RT-PCR (qRTPCR) analysis showed that SHEP-21N cells without $\mathrm{N}-\mathrm{Myc}$ expression had basal expression of TRPM7 and
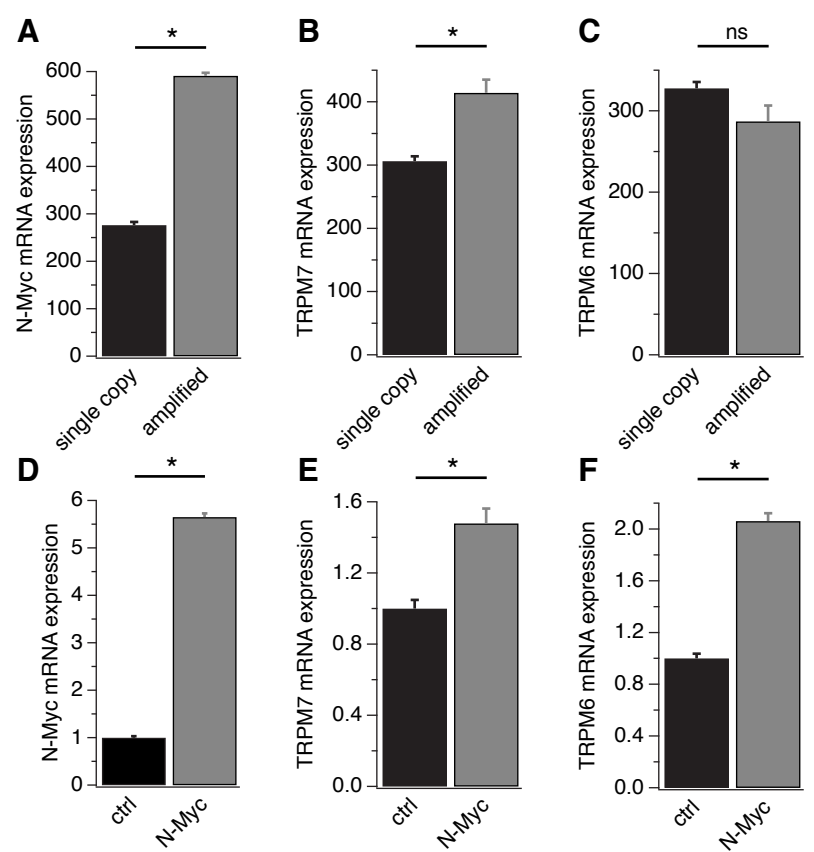

Figure 1: TRPM6 and TRPM7 correlation with MYCN in neuroblastoma. A-C, N-Myc, TRPM7 and TRPM6 mRNA expression correlation with MYCN amplification in the Kocak-649 cohort. Microarray analysis of N-Myc, TRPM7 and TRPM6 mRNA expression in Kocak-649 (GSE45547), the largest neuroblastoma cohort in the public domain. The graphs present N-Myc (A), TRPM7 (B) and TRPM6 (C) expression in tumors without $(\mathrm{n}=550)$ and with $(\mathrm{n}=93)$ MYCN amplification. Y-axes represent sample ranks in a non-parametric KruskalWallis t test; actual mean \pm s.e.m. expression values were: $17,839 \pm 1,137$ (MYCN), $104.9 \pm 3.7$ (TRPM6), $807.0 \pm 321.1$ (TRPM7). Both N-Myc and TRPM7 expression are significantly higher in tumors with MYCN amplification $\left(p=1.5 \cdot 10^{-51}\right.$ and $p=2.3 \cdot 10^{-7}$ respectively; Kruskal-Wallis t test). D-F, qRT-PCR analysis of N-Myc (D), TRPM7 (E) and TRPM6 (F) expression levels in the SHEP-21N cell line where MYCN transgene is controlled by tetracycline, i.e., N-Myc expression is repressed in the presence of tetracycline (control), but removal of tetracycline induces $\mathrm{N}-\mathrm{Myc}$ expression (N-Myc). The graphs show normalized N-Myc, TRPM7 and TRPM6 expression in SHEP-21N cells with (N-Myc, $n=9$ ) or without (control, $n=9$ ) $\mathrm{N}-\mathrm{Myc}$ expression. ${ }^{*}, p<0.01$. 

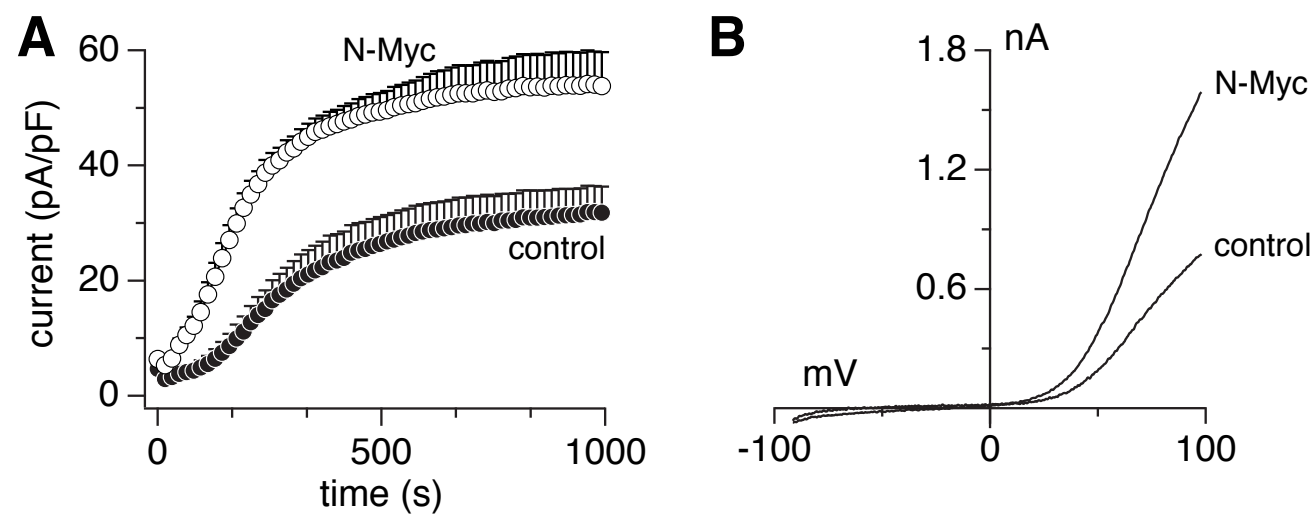

Figure 2: Endogenous MagNuM currents are increased by $\mathbf{N}$-Myc upregulation. Currents were measured in divalent-free internal solution with $5 \mathrm{mM}$ EGTA and $5 \mathrm{mM}$ EDTA. A, whole-cell current development in SHEP-21N cells expressing $(\mathrm{N}-\mathrm{Myc}, \mathrm{n}=11)$ or not (control, $\mathrm{n}=10)$. B, corresponding representative ramp currents ( $\mathrm{I}-\mathrm{V}$ curves) extracted at 1,000 s from both groups.
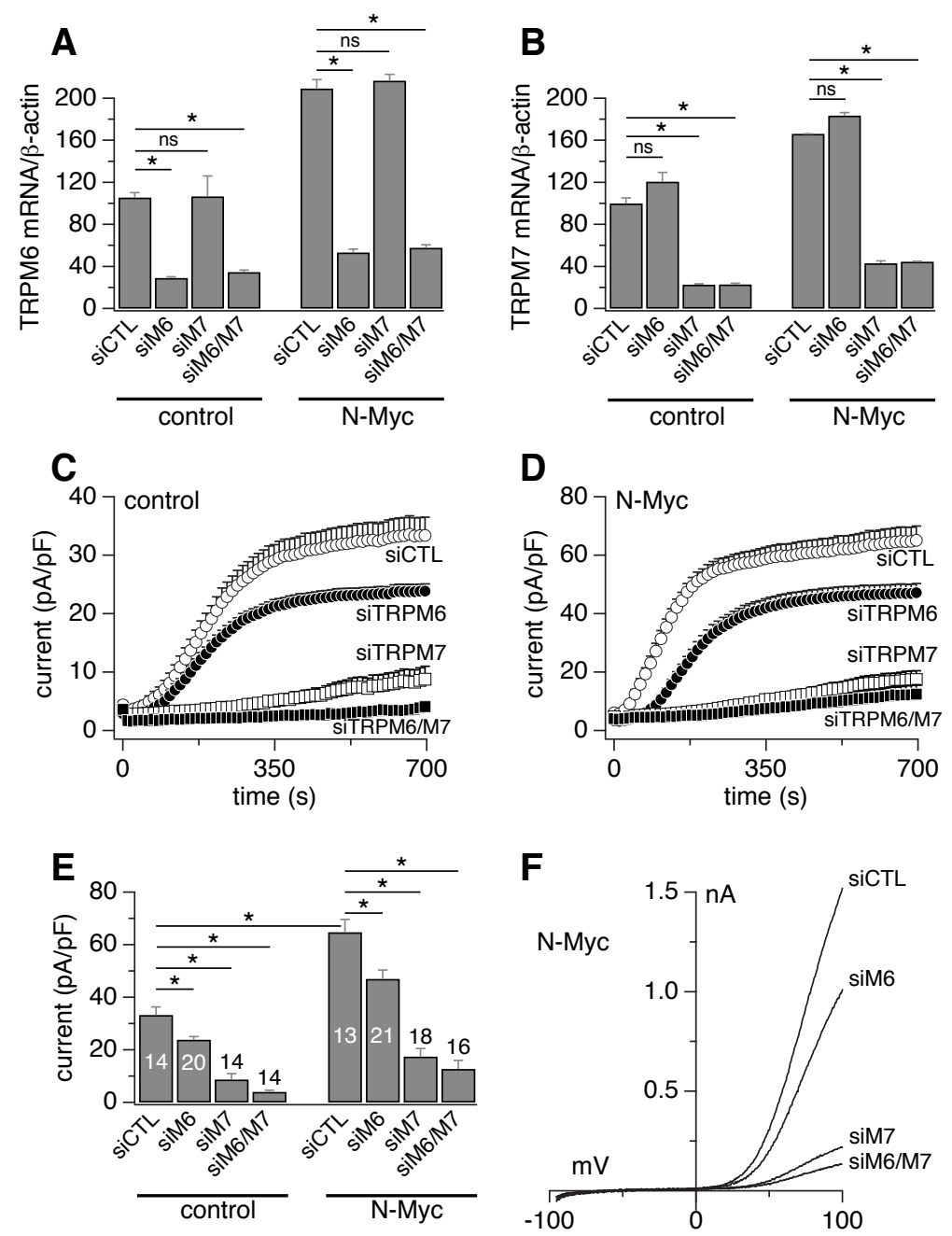

Figure 3: Endogenous MagNuM currents are mediated by TRPM7 and TRPM6. Currents were measured in divalent-free internal solution with $5 \mathrm{mM}$ EGTA and $5 \mathrm{mM}$ EDTA. A-B, siRNAs efficacy measured by qRT-PCR analysis of TRPM6 (A) and TRPM7 (B) expression levels in the SHEP-21N cell line under both control and N-Myc upregulation conditions ( $\mathrm{n}=9$ ). C, MagNuM currents in control SHEP-21N cells treated with negative non-silencing (siCTL) or specific siRNA sequences against TRPM7, TRPM6, TRPM7\&TRPM6. D, current measurement in N-Myc-expressing SHEP-21N cells treated with negative (siCTL) or specific siRNA sequences against TRPM7, TRPM6, TRPM7\&TRPM6. E, statistical summary of current amplitudes at $700 \mathrm{~s}$ as in $\mathrm{c}-\mathrm{d}(*, p<0.01)$. The number of patched cells is indicated in graph. F, typical current traces evoked by voltage ramps (I-V curves) in N-Myc-expressing SHEP-21N cells as in D. 
TRPM6, which was considerably enhanced by N-Myc upregulation (Figs. 1D-F). Induction of TRPM6 and TRPM7 expression by N-Myc was significant for both channel kinases, but higher for TRPM6 (2.1-fold for TRPM6 and 1.5-fold for TRPM7). This suggests that N-Myc upregulates both TRPM genes and concomitantly increases the ratio of TRPM6 over TRPM7.

\section{Endogenous MagNuM currents in SHEP-21N are mediated by TRPM6 and TRPM7}

Heterologous expression of heteromeric TRPM7/ TRPM6 produces an outwardly rectifying current whose current-voltage relationship is indistinguishable from homomeric TRPM7 or TRPM6 currents $[9,14]$. Patchclamp recordings in SHEP-21N cells also revealed such currents (Figs. 2A, B). Importantly, SHEP-21N cells exhibited significantly larger current amplitudes when they expressed N-Myc (Figs. 2A, B), consistent with the observed N-Myc-induced increases in TRPM7 and
TRPM6 mRNA levels (Figs. 1E, F). Employing specific small interfering RNA (siRNA) against TRPM7 and TRPM6 (Figs. 3A, B), we found that MagNuM currents were significantly suppressed upon TRPM6 knockdown, and both knockdown of TRPM7 or TRPM7/TRPM6 combined nearly abolished any endogenous MagNuM currents (Figs. 3C-F). These results demonstrate that $\mathrm{N}-\mathrm{Myc}$ expression produces significantly larger overall MagNuM currents and suggest that, independent of N-Myc levels, endogenous MagNuM currents in SHEP$21 \mathrm{~N}$ cells are largely composed of TRPM7 with a lesser, yet significant, contribution of TRPM6.

\section{N-Myc expression shapes the phenotype of native TRPM7/TRPM6 currents}

Heteromeric TRPM7/TRPM6 channels behave differently from both homomeric TRPM7 and homomeric TRPM6. In heterologous expression systems, 2-APB suppresses TRPM7 currents, potentiates TRPM6
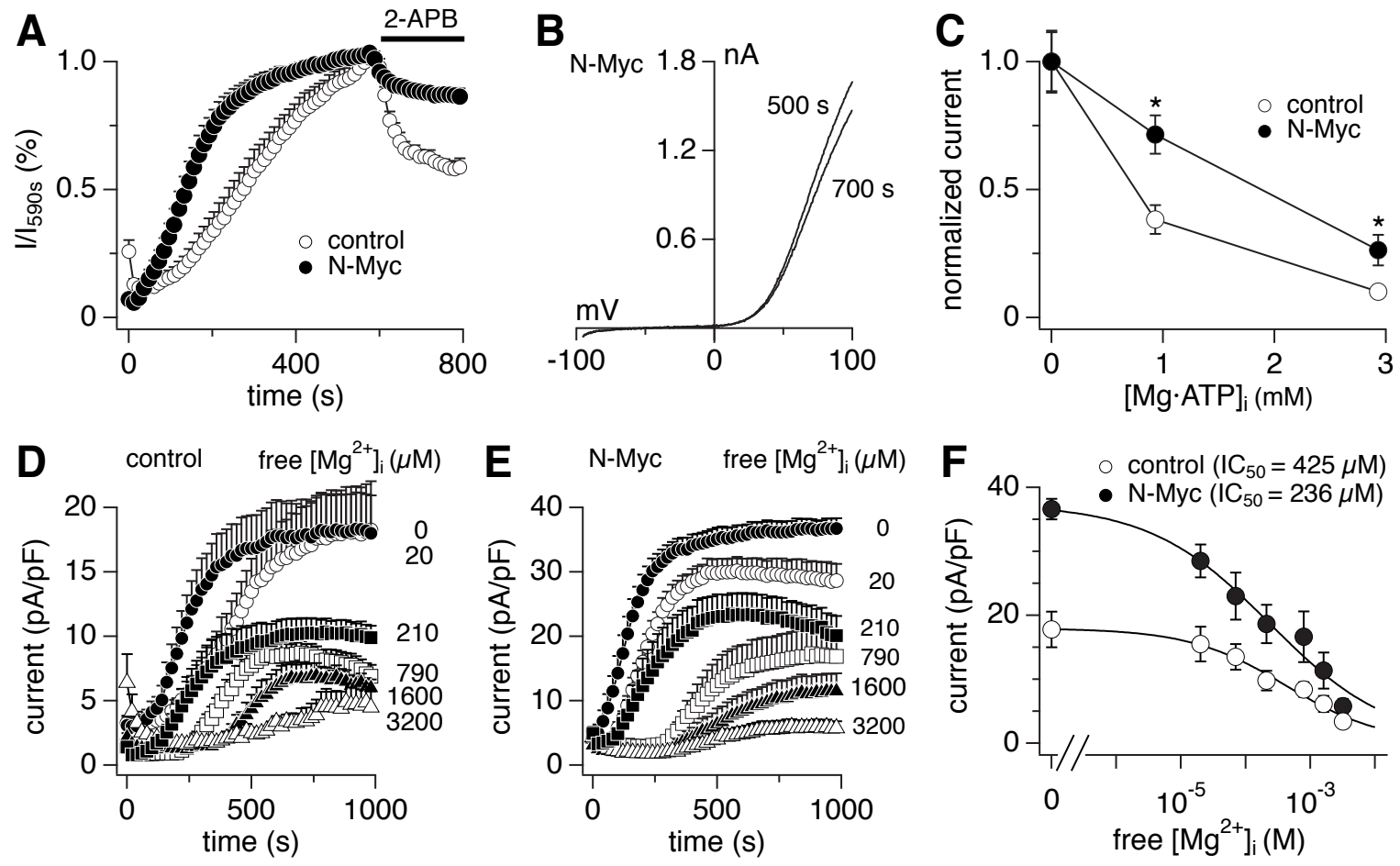

Figure 4: N-Myc expression shapes the phenotype of native TRPM7/TRPM6 currents. Whole-cell MagNuM currents were measured in SHEP-21N cells treated with tetracycline (control) or not (N-Myc) and peak outward currents at $+80 \mathrm{mV}$ were analyzed. A, inhibition of MagNuM current by $200 \mu \mathrm{M}$ 2-APB (control, $\mathrm{n}=10$; N-Myc, $\mathrm{n}=7$ ), normalized to current amplitude just prior to 2-APB application. B, representative currents evoked by voltage ramps (I-V curves) were derived from N-Myc-expressing cells before (500 s) and after (700 s) 2-APB application. C, ATP sensitivity of currents ( $\mathrm{n}=7-13$ cells for each point; *,$p<0.01)$. Mg . ATP concentrations were fixed at 1 or $3 \mathrm{mM}$ with an internal free $\mathrm{Mg}^{2+}$ concentration of $264 \mu \mathrm{M}$. Currents were normalized against the control condition containing no $\mathrm{Mg} \cdot \mathrm{ATP}$ internally. D, E, current measurements in control and N-Myc-expressing cells perfused with intracellular solutions of defined free $\mathrm{Mg}^{2+}$ concentrations as labeled in the graph (control, $\mathrm{n}=5-6$ for each $\mathrm{Mg}^{2+}$ concentration; $\mathrm{N}-\mathrm{Myc}, \mathrm{n}=5-7$ for each $\mathrm{Mg}^{2+}$ concentration). Free $\mathrm{Mg}^{2+}$ concentration in internal solution was clamped to the indicated levels with $10 \mathrm{mM}$ EGTA. F, peak current amplitudes derived from $\mathrm{D}$ and $\mathrm{E}$ as a function of free $\mathrm{Mg}^{2+}$ concentration. Dose-response fit rendered $\mathrm{IC}_{50}$ values of $425 \mu \mathrm{M}$ and $236 \mu \mathrm{M}$ for control and N-Myc-expressing cells, respectively. 
currents, and leaves heteromeric TRPM7/TRPM6 largely unaffected, indicating that incorporation of TRPM6 renders the TRPM7/TRPM6 heteromer less sensitive to 2-APB $[9,14]$. Indeed, N-Myc induction attenuated the inhibitory effects of 2-APB on the MagNuM currents in SHEP-21N cells (Figs. 4A, B). Since homomeric TRPM6 channels are strongly suppressed by free intracellular $\mathrm{Mg}^{2+}$, heteromeric TRPM7/TRPM6 channels exhibit increased sensitivity of $\mathrm{Mg}^{2+}$-mediated suppression relative to TRPM7. This has been shown to be due to cross-phosphorylation of TRPM7 by the TRPM6 kinase domain [14]. Consistent with this mechanism, the doseresponse curves for intracellular free $\mathrm{Mg}^{2+}$ in SHEP-21N cells revealed that N-Myc expression and the resulting up-regulation of TRPM6 considerably enhanced the sensitivity of native currents to $\mathrm{Mg}^{2+}$, as indicated by a decrease in $\mathrm{IC}_{50}$ from $425 \mu \mathrm{M}$ to $236 \mu \mathrm{M}$ (Figs. 4D-F). Finally, and physiologically most relevant, intracellular $\mathrm{Mg} \cdot$ ATP strongly suppresses heterologously expressed TRPM7 channels [7], but has no inhibitory effect on either
TRPM6 or TRPM7/TRPM6 currents [14]. Accordingly, $\mathrm{N}-\mathrm{Myc}$ expression in SHEP-21N cells significantly reduced $\mathrm{Mg} \cdot \mathrm{ATP}$-mediated suppression of endogenous MagNuM currents (Fig. 4C). Thus N-Myc expression caused changes in the behavior of native MagNuM currents in SHEP-21N cells with respect to 2-APB, intracellular free $\mathrm{Mg}^{2+}$ and $\mathrm{Mg} \cdot \mathrm{ATP}$ that resemble the channel phenotype of overexpressed TRPM7/TRPM6 heteromers [14] and consequently would favor enhanced constitutive activity of these channels at rest.

\section{Suppression of TRPM7/TRPM6 inhibits proliferation of neuroblastoma}

We performed knockdown experiments using siRNA as described above to investigate the relative role of both TRPM6 and TRPM7 channels in SHEP-21N cell proliferation. N-Myc induction following tetracycline withdrawal promoted cell proliferation compared to
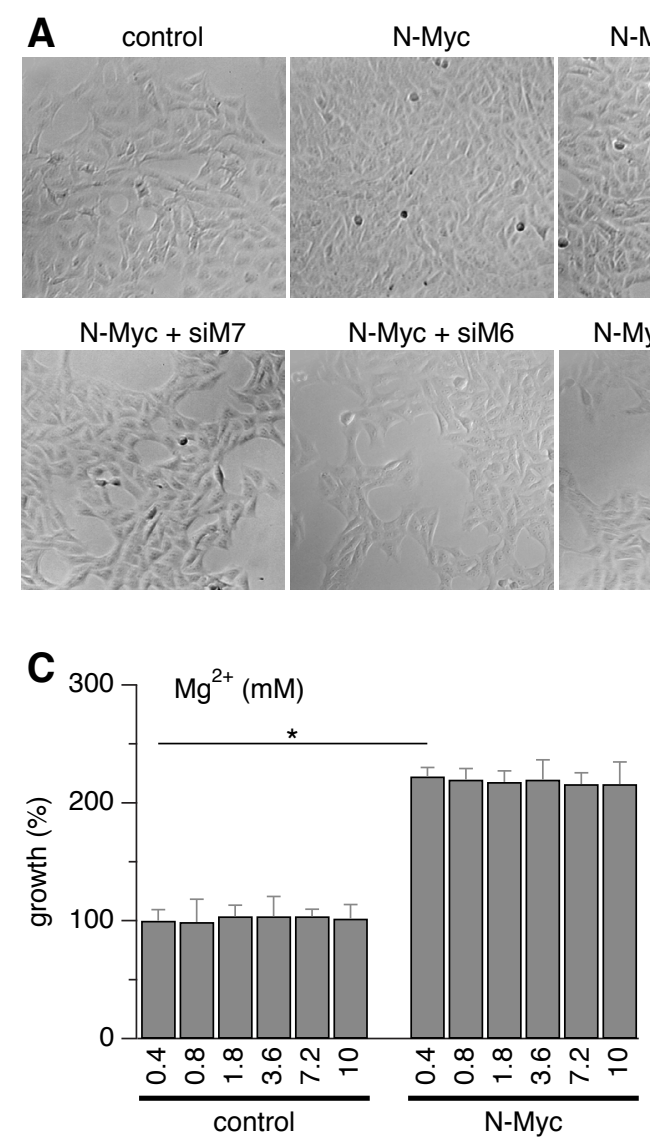

$\mathrm{N}-\mathrm{Myc}+\mathrm{siCTL}$

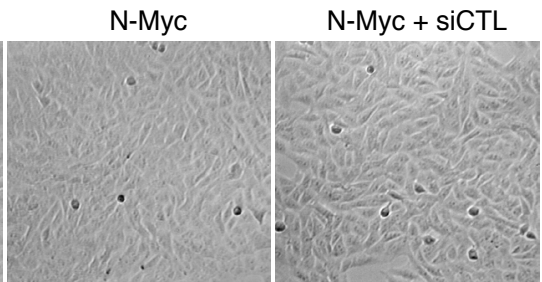

$\mathrm{N}-\mathrm{Myc}+$ siM6/M7
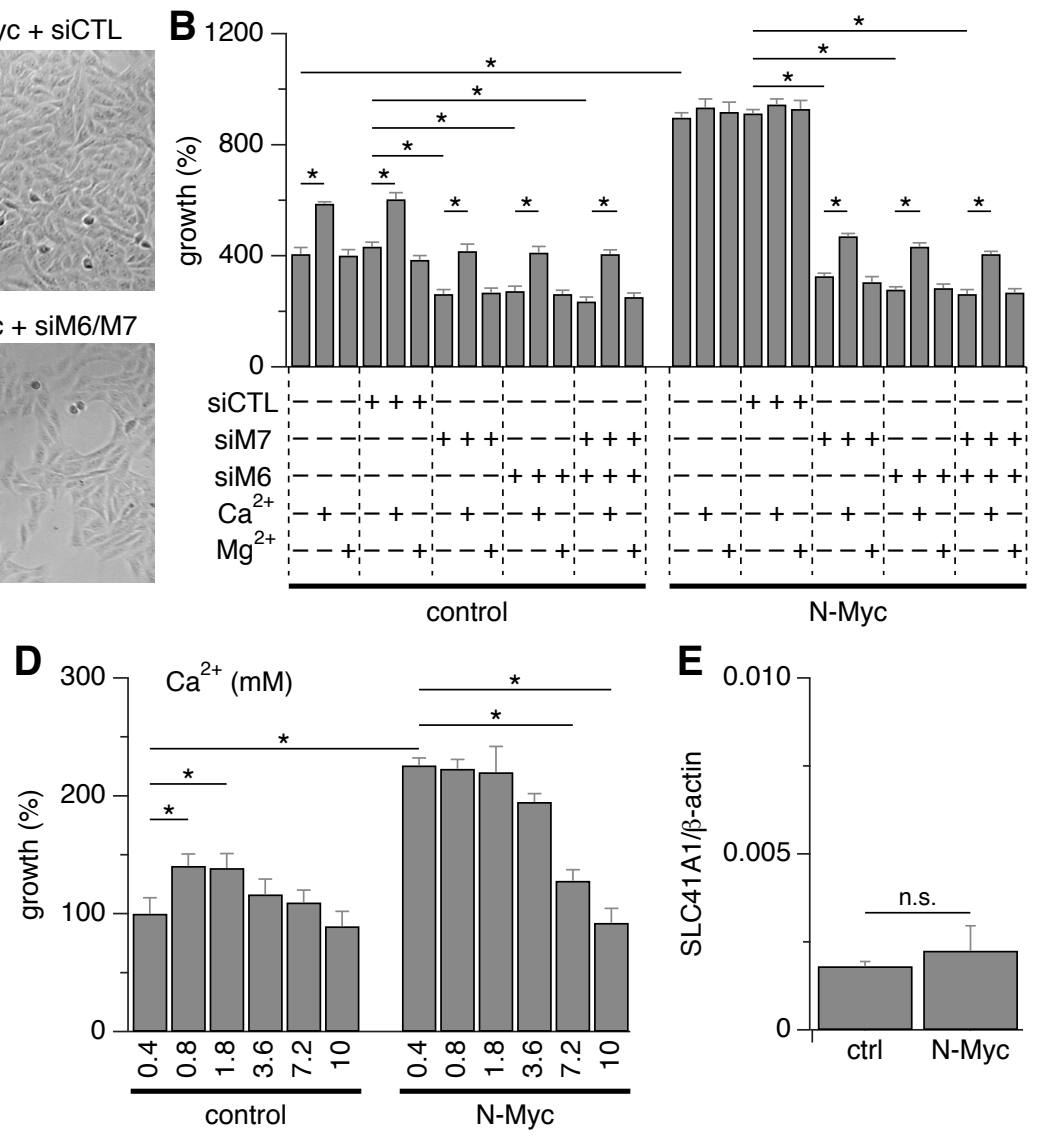

Figure 5: siRNA, $\mathrm{Ca}^{2+}$ and $\mathrm{Mg}^{2+}$ supplementation and TRPM7/M6-dependent cell proliferation. A, representative images of SHEP-21N cells treated with siRNA as indicated. Tetracycline was added (control) or not (N-Myc) to repress or induce N-Myc expression, respectively. $\operatorname{siCTL}=$ negative control siRNA; siM6 = siRNA against TRPM6; siM7 = siRNA against TRPM7. B, statistical analysis of cell growth in SHEP-21N cells treated with the indicated siRNA $\left(\mathrm{n}=6 ;{ }^{*}, p<0.01\right)$. Cells were transfected with siRNA, seeded, treated or not treated with $\mathrm{Mg}^{2+}$ or $\mathrm{Ca}^{2+}$ on day 1, and analyzed on day 3 after seeding. C-D, analysis of cell growth in SHEP-21N cells treated for 2 days with the indicated $\mathrm{Mg}^{2+}(\mathrm{C})$ or $\mathrm{Ca}^{2+}(\mathrm{D})$ concentrations $(\mathrm{n}=6)$. E, qRT-PCR analysis of SLC41A1 transcripts in both control and N-Mycexpressing SHEP21N cells ( $\mathrm{n}=6$; n.s., not significant). 
tetracycline-treated SHEP-21N cells without N-Myc expression (Figs. 5A, B). In either group, the additional siRNA-mediated knockdown of TRPM7, TRPM6 or TRPM7/TRPM6 expression markedly inhibited SHEP$21 \mathrm{~N}$ cell proliferation (Figs. 5A, B). Notably, knockdown of TRPM6 alone strongly inhibited cell proliferation, an effect that was comparable to that seen with TRPM7 suppression (Figs. 5A, B). Given that TRPM6 knockdown only causes moderate reduction in total MagNuM currents recorded under divalent-free intracellular solutions (Figs. 3C, D), this indicates that TRPM6 may play a vital role in promoting cell proliferation under physiological conditions by enhancing the constitutive activity of MagNuM currents.

Since TRPM6 and TRPM7 are permeable to both $\mathrm{Ca}^{2+}$ and $\mathrm{Mg}^{2+}$ and both divalent cations can regulate cell proliferation, we assessed the role of $\mathrm{Ca}^{2+}$ and $\mathrm{Mg}^{2+}$ in SHEP-21N proliferation assays. We first established a dose-response relationship of $\mathrm{Ca}^{2+}$ and $\mathrm{Mg}^{2+}$ by incubating SHEP-21N cells in media with $\mathrm{Ca}^{2+}$ and $\mathrm{Mg}^{2+}$ concentrations adjusted in the range of $0.4 \mathrm{mM}$ to $10 \mathrm{mM}$ (while the congeneric divalent remained at $0.4 \mathrm{mM}$ ). Increasing $\mathrm{Mg}^{2+}$ up to $10 \mathrm{mM}$ had no effect on SHEP-21N cell proliferation regardless of $\mathrm{N}-\mathrm{Myc}$ expression (Fig. 5C). Increasing $\mathrm{Ca}^{2+}$ levels up to $1.8 \mathrm{mM}$ had no significant effect on N-Myc-expressing cells, but yielded a slight increase in cell numbers in cells without N-Myc expression (Fig. 5D). At higher concentrations of $\mathrm{Ca}^{2+}$, cell proliferation started to decline in both cell populations. For this reason, we assessed possible compensatory effects of divalent supplementation on cell proliferation in cells in which TRPM6, TRPM7, or both, were knocked down with siRNA using concentrations of $10 \mathrm{mM} \mathrm{Mg}^{2+}$ and $1.8 \mathrm{mM} \mathrm{Ca}^{2+}$ (Fig. 5B). As illustrated in Fig. $5 \mathrm{~B}, 10 \mathrm{mM} \mathrm{Mg}^{2+}$ had no effect on cell proliferation, indicating the low abundance or absence of alternative $\mathrm{Mg}^{2+}$ uptake mechanisms in these cells. Indeed, qRTPCR analysis of SLC41A1, a $\mathrm{Mg}^{2+}$ transporter that has been found to rescue TRPM7-deficient DT40 cells from growth arrest [17,31], revealed that its mRNA levels were 123/24-fold less expressed than those of TRPM7/ TRPM6, respectively (Figs. 5E and 1E, F). Importantly, SLC41A1 mRNA levels did not change significantly upon $\mathrm{N}-\mathrm{Myc}$ induction. Interestingly, $\mathrm{Ca}^{2+}$ supplementation to $1.8 \mathrm{mM}$ partially rescued the growth-arrest phenotype by causing a slight increase in cell numbers under all experimental conditions, except in N-Myc-expressing SHEP-21N cells in which TRPM6 and TRPM7 were left uninhibited and which were already strongly proliferating. However, neither cation was able to decisively rescue the growth suppression imposed by the knockdown of either channel. Thus, TRPM7, particularly in combination with TRPM6, appears to represent the major $\mathrm{Ca}^{2+}$ and/or $\mathrm{Mg}^{2+}$ accumulation mechanisms in SHEP-21N cells.

\section{DISCUSSION}

While TRPM6 was initially discovered in the absorptive epithelia in the kidney and intestine $[5,6]$, the present study now demonstrates that the protein is also expressed in SHEP-21N neuroblastoma. TRPM6 expression in SHEP-2 and SHEP-21N is not serendipitous, as data mining of Kocak-649 and other public neuroblastoma cohort expression profiles showed very similar expression levels and patterns: TRPM7 mRNA expression is ubiquitous and TRPM6 mRNA is much lower, and present in only $\sim 10 \%$ of samples (results not shown). Remarkably, SHEP-21N cells expressed TRPM6 at a sufficiently high level that endogenous TRPM6dependent currents could be measured for the first time. The central observation made in the present study was that the enhanced proliferation phenotype mediated by N-Myc expression (Figs. 1 and 5A, B) was paralleled by increased TRPM6 and TRPM7 expression levels (Figs. 1E, F), as well as by enlarged endogenous MagNuM currents (Figs. 2A, B). The phenotypic characteristics of the resulting currents are consistent with heteromeric TRPM6/TRPM7 channels (Fig. 4). Molecular suppression of either channel through siRNA (Figs. 3C-F and 5A, B) completely suppressed both the N-Myc-enhanced MagNuM currents and the growth phenotype (Figs. 3 and 4).

Even though both TRPM6 and TRPM7 also possess kinase activity in addition to their channel function, TRPM6 has no known phosphorylation substrates other than TRPM7 [32] and the currently known TRPM7 substrates, annexin A1 and myosin IIA heavy chain $[33,34]$, are not likely to determine cell proliferation. This indicates that enhanced ion transport activities are in part responsible for the growth phenotype observed in N-Mycexpressing SHEP-21N cells. Our results are therefore consistent with the hypothesis that N-Myc enhances TRPM6 expression, which in turn promotes $\mathrm{Ca}^{2+}$ and $\mathrm{Mg}^{2+}$ transport across the plasma membrane by enhancing the overall activity of TRPM6/TRPM7 heteromeric channel assemblies, and thereby promotes cell proliferation.

The expression patterns of TRPM6 and TRPM7 in MYCN-amplified neuroblastoma cell lines and SHEP-21N cells suggests that their expression might not necessarily relate to N-Myc expression, as some MYCN-amplified cell lines had low TRPM6 expression levels (data not shown). Nevertheless, in SHEP-21N cells, N-Myc is able to elevate basal TRPM6/7 expression upon induction. In addition, in the largest publicly available neuroblastoma expression profiling dataset, the Kocak-649 cohort [29], TRPM7 mRNA expression is found in all tumor samples, and is significantly correlated to N-Myc amplification. No significant correlations were found for TRPM6, most likely due to the small numbers of tumors with significant TRPM6 expression. Future investigations might reveal oncogene-dependent increases of TRPM6 expression in other cells that already express some basal levels of 


\section{TRPM6.}

We previously demonstrated in heterologous expression systems that TRPM7/TRPM6 channel heteromers, when co-expressed at a stoichiometric ratio of $\sim 1: 1$, exhibit unique phenotypes that are characterized by insensitivity to 2-APB, lack of modulation by $\mathrm{Mg} \cdot \mathrm{ATP}$ and increased sensitivity to $\mathrm{Mg}^{2+}$ inhibition compared with homomeric TRPM7 [14]. The insensitivity of heteromeric TRPM7/TRPM6 channels to cytosolic ATP leaves the channel function largely unaffected by cellular energy status and augmented $\mathrm{Mg}^{2+}$ inhibition indicates an enhanced negative feedback loop, a common regulatory mechanism for many ion channels, such as CRAC and TRPV5/TRPV6 [35,36]. These distinctive features of heteromeric TRPM7/TRPM6 channels are primarily controlled by cross-phosphorylation of TRPM7 by the TRPM6 kinase domain [32] and will determine the functional activity of the channel complex as a $\mathrm{Ca}^{2+}$ and $\mathrm{Mg}^{2+}$ influx conduit under physiological circumstances. Consistent with the findings in TRPM7/TRPM6 overexpression systems, the native currents in SHEP-21N cells expressing N-Myc were less inhibited by 2-APB, less suppressed by $\mathrm{Mg} \cdot \mathrm{ATP}$, and more sensitive to $\mathrm{Mg}^{2+}$ inhibition compared to the currents in cells without N-Myc expression (Fig. 4). Thus, N-Myc shaped the MagNuM phenotype towards that of heteromeric TRPM7/TRPM6 by increasing the relative amount of TRPM6.

It is noteworthy that the extent to which the MagNuM phenotype was altered in native SHEP-21N cells is slightly less pronounced than that previously observed in a TRPM7/TRPM6 overexpression system, where the ratio of TRPM6/TRPM7 was $\sim 1[14,32]$, suggesting that the ratio of TRPM6 over TRPM7 within channel complexes in SHEP-21N cells is lower than 1. This would be consistent with the observed mRNA levels (Figs. 1E, F) and also be consistent with the observation that TRPM6 suppression downregulated the MagNuM currents by $29 \%$, whereas knockdown of TRPM 7 reduced current amplitudes by $74 \%$ (Fig. 4). Nevertheless, the impact of TRPM6 knockdown on cell proliferation was as severe as that of TRPM7, suggesting that relatively small increases in TRPM6 expression can significantly alter the MagNuM current behavior under physiological conditions. Since TRPM6/TRPM7 heteromers are less sensitive to $\mathrm{Mg}$-ATP and slightly more sensitive to $\mathrm{Mg}^{2+}$ inhibition (Fig. 4; [14]), TRPM6-containing heteromeric channels in SHEP-21N would likely be less suppressed under physiological conditions, as the most dominant physiological regulator of $\mathrm{MagNuM}$ is $\mathrm{Mg} \cdot \mathrm{ATP}$ [7]. As a result, these heteromeric channels would be more effective in supporting proliferation than TRPM7 homomers.

TRPM7 and TRPM6 conduct divalent cations with preferential transport of $\mathrm{Mg}^{2+}$ over $\mathrm{Ca}^{2+}$. Consistent with this notion is that TRPM6 plays a well-documented role in $\mathrm{Mg}^{2+}$ absorption/reabsorption in epithelia of colon and kidney $[6,19,20]$ and TRPM7 has been found to be critical for cellular $\mathrm{Mg}^{2+}$ homeostasis $[17,18]$ and a critical factor for cell proliferation $[13,37,38]$. The presence and regulation of TRPM6 in SHEP-21N cells thus would suggest that this channel may also serve a role in the pathological context of neuroblastoma by regulating cellular $\mathrm{Mg}^{2+}$ levels in conjunction with TRPM7. However, the role of $\mathrm{Ca}^{2+}$ transport through TRPM6 and/or TRPM7 may not be insignificant, particularly in cells in which $\mathrm{Ca}^{2+}$ is an important regulator of cell proliferation. Thus, it has been suggested that $\mathrm{Ca}^{2+}$ influx through TRPM7 may be critical for fibroblast proliferation [39] and a recent study on prostate cancer cells proposed that enhanced $\mathrm{Ca}^{2+}$ influx through TRPM7 determined their proliferation rate [40].

Our $\mathrm{Ca}^{2+}$ and $\mathrm{Mg}^{2+}$ supplementation experiments revealed that increasing extracellular $\mathrm{Mg}^{2+}$ from 0.4 to $10 \mathrm{mM}$ had no effect on proliferation regardless of $\mathrm{N}-\mathrm{Myc}$ expression in SHEP-21N cells (Fig. 5), whereas $\mathrm{Ca}^{2+}$ had a slight facilitatory effect up to $1.8 \mathrm{mM}$. Higher concentrations of $\mathrm{Ca}^{2+}$ reduced cell proliferation. Extracellular $\mathrm{Mg}^{2+}$ can be taken up by mammalian cells through $\mathrm{Mg}^{2+}$-permeable channels, including TRPM7 and TRPM6 [5], and/or $\mathrm{Mg}^{2+}$ transporter, such as SLC41A1 [41]. Genetic ablation of TRPM7 in DT40 cells induces growth arrest, and supplementation with high extracellular $\mathrm{Mg}^{2+}(10 \mathrm{mM})$, but not $\mathrm{Ca}^{2+}$, rescues the growth arrest [42], a compensatory effect partly mediated by the $\mathrm{Mg}^{2+}$ transporter SLC41A1 that is natively expressed in DT40 cells [31]. However, $\mathrm{Mg}^{2+}$ supplementation was completely ineffective in overcoming the growth arrest of SHEP-21N cells in which either TRPM6, TRPM7, or both were knocked down with siRNA (Fig. 5B), suggesting that TRPM6/TRPM7 channels, rather than SLC41A1, constitute the major $\mathrm{Mg}^{2+}$ uptake mechanism in these cells. An alternative explanation could be that $\mathrm{Mg}^{2+}$ may not be the limiting factor for cell proliferation in these cells and the more relevant cation might be $\mathrm{Ca}^{2+}$. Indeed, supplementation of $\mathrm{Ca}^{2+}(1.8 \mathrm{mM})$ in the extracellular solution slightly enhanced proliferation, although not in N-Myc-expressing SHEP-21N cells. The reason for this could be that these SHEP-21N cells already proliferated at maximal rates. It remains to be determined whether the facilitatory effect of $\mathrm{Ca}^{2+}$ is mediated by $\mathrm{Ca}^{2+}$ influx through TRPM6/TRPM7 channels or represents an alternative $\mathrm{Ca}^{2+}$ influx pathway that offsets a $\mathrm{Mg}^{2+}$ dependent growth impairment.

The data presented in this study suggest that TRPM7 channels have a significant impact on cell proliferation of neuroblastoma, regardless of whether or not they express N-Myc, whereas additional TRPM6 expression further synergizes with TRPM7 in augmenting the proliferative activity. The relevance of TRPM7 for cell proliferation is also evident in other cancers, as genetic suppression of TRPM7 can inhibit the proliferation of human head and neck squamous carcinoma (HNSCC) [37] and ascending aortic vascular smooth muscle cells (VSMC) [38]. Pharmacological inhibition of TRPM7 by the channel 
blocker waixenicin A has also been shown to inhibit cell proliferation of rat basophilic and human Jurkat T-cell leukemia cells [13]. This makes $\mathrm{Ca}^{2+} / \mathrm{Mg}^{2+}$-transporting channels attractive candidates as pharmacological targets for potential therapeutic drugs. Collectively, genetic or pharmacological suppression of TRPM7/TRPM6 channels inhibits cell proliferation, underscoring the importance of these channels in promoting proliferation and pointing towards a potential therapeutic avenue for the treatment of neuroblastoma.

\section{MATERIALS AND METHODS}

\section{Cell culture and microarray analysis}

Neuroblastoma cell line and culture conditions were as in $[28,43]$. N-Myc expression in SHEP-21N $[28,30]$ was inhibited by the addition of tetracycline (100 ng/ml) and incubation for at least 48 hours. The Agilent-020382 Human Custom Microarray 44k data for Kocak-649 was described in [29]. Expression data for this dataset were retrieved from the public Gene Expression Omnibus (GEO) dataset on the NCBI website (GEO ID: GSE45547). The TranscriptView genomic analysis and visualization tool was used to confirm the anti-sense position in a (posterior) exon of the probe-sets. The Agilent probe-sets MYCN 24_P94402 (MYCN), 24_P410463 (TRPM6), and 23_P88470 (TRPM7), that fulfilled these criteria, and in addition showed the highest sensitivity for detection of the target gene, were selected. Alternative correct probe-sets did not yield conflicting results. All analyses were performed using R2 (http:// r2.amc.nl).

\section{Electrophysiology and solutions}

Whole-cell patch-clamp experiments were performed at room temperature $\left(20-25{ }^{\circ} \mathrm{C}\right)$. Highresolution whole-cell currents were recorded by EPC-9 (HEKA, Bellmore, NY) and Patchmaster v2.4 (HEKA). Unless otherwise stated, all voltages were corrected for a liquid junction potential of $10 \mathrm{mV}$. Patch pipettes pulled from borosilicate glass had resistances of 2.5$3.5 \mathrm{M} \Omega$ when filled with internal solutions. Cells were held at $0 \mathrm{mV}$ holding potential, with voltage ramps of $50 \mathrm{~ms}$ duration spanning the voltage range of $-100 \mathrm{mV}$ to $+100 \mathrm{mV}$ delivered at a rate of $0.5 \mathrm{~Hz}$ following the establishment of whole-cell configuration. The currents were filtered at $2.9 \mathrm{kHz}$ and digitized at $10 \mathrm{kHz}$. SHEP$21 \mathrm{~N}$ cells plated on coverslips were bathed in $\mathrm{Mg}^{2+}$-free external solution containing (in $\mathrm{mM}$ ) $140 \mathrm{NaCl}, 2.8 \mathrm{KCl}$, $1 \mathrm{CaCl}_{2}, 10 \mathrm{HEPES}, 11$ Glucose, pH 7.4 adjusted with $\mathrm{NaOH}$. The divalent-free internal recording solution was composed of (in mM): 140 Cs-glutamate, $8 \mathrm{NaCl}$, 5 Cs-
EDTA, 5 Cs-EGTA, 10 Cs-HEPES, pH 7.2 adjusted with $\mathrm{CsOH}$. When needed, internal free $\mathrm{Mg}^{2+}$ was clamped by $10 \mathrm{mM}$ EGTA to various levels, as calculated by WebMaxC (http://maxchelator.stanford.edu).

\section{RNA extraction and quantitative real-time PCR (qRT-PCR)}

Quantitative real-time PCR (qRT-PCR) was used to examine the mRNA expression levels of TRPM6 and TRPM7 using $\beta$-actin for normalization. Total RNA $(1 \mu \mathrm{g})$ was extracted from SHEP-21N cells treated with or without tetracycline using the RNeasy Mini kit (Qiagen, Valencia, CA). Conversion of mRNA to cDNA was achieved using random priming by ABI's High Capacity cDNA RT Kit with RNase Inhibitor (Applied Biosystems, Life Technologies, Foster City, CA). The qRT-PCR was performed using the ABI HT7900 FAST Real-Time PCR System (Applied Biosystems) and ABI POWER SYBRGreen (Applied Biosystems) according to the manufacturers' protocols. Gene-specific primer pairs of human MYCN (QT00201404) human TRPM6 (QT00043456), TRPM7 (QT00082425) and $\beta$-actin (QT01680476) were purchased from Qiagen.

\section{RNA interference and cell proliferation assay}

The small interfering RNA (siRNA) duplexes specific against human TRPM6 (4392420) and TRPM7 (4390824), and a non-silencing RNA sequence (4390843) as a negative control were transiently transfected with RNAiMAX (Invitrogen) according to the manufacturer's protocols. siRNA transfection and cell seeding were carried out simultaneously, according to the reverse transfection protocol of RNAiMAX. Briefly, siRNA at a final concentration of $20 \mathrm{nM}$, diluted in Opti-MEM (Invitrogen), was mixed with RNAiMAX in 6-well plates, followed by seeding of SHEP-21N cells at $5 \times 10^{4}$ cells/ well in 6-well plates,. On day 2 after siRNA transfection, micrographs of SHEP-21N cells were taken at $\times 10$ magnification. Currents were measured and cell numbers counted on day 3 after transfection. To count the cell number, SHEP-21N cells were trypsinized to single cells and stained with trypan blue, followed by cell counting with a hemocytometer. Each well was counted four times. The experiments were repeated as indicated in the figure legends.

\section{Statistical analysis}

Currents were analyzed with FitMaster v2.11 (HEKA) and Igor Pro (Wavemetrics, Portland, OR). Peak outward currents at $+80 \mathrm{mV}$ were extracted for statistical analysis. Current amplitudes were normalized to cell size 
upon break-in as current density $(\mathrm{pA} / \mathrm{pF})$. Dose-response curves were calculated using the function $f(\mathrm{x})=\left(\mathrm{Y}_{\max } *(1 /\right.$ $\left.\left.\left(1+\left(\mathrm{IC}_{50} / \mathrm{x}\right)^{\mathrm{n}}\right)\right)\right)$, where $\mathrm{Y}_{\max }$ is the maximal normalized current, $\mathrm{IC}_{50}$ is the concentration at which inhibition is half maximal, $\mathrm{x}$ is the concentration, and $\mathrm{n}$ is the Hill coefficient. All data are given as mean \pm standard error of mean (s.e.m.). Appropriate ANOVA, Student's, or Kruskal-Wallis $t$ tests, and $2 \log P$ earson correlation were performed to assess statistical significance. $P$ values $<0.05$ were considered as statistically significant.

\section{ACKNOWLEDGEMENTS}

The authors would like to thank Lori Tsue and Chris Maggio for their excellent technical assistance. Funding: The study was supported by NIH Grants U54 CA143727 (R.P.) and P01 GM078195 (A.F.). Author contribution: Z.Z., M.F. design, execution, interpretation of data and manuscript preparation. J.H., D.G., H.Y. execution and interpretation of data. R.P., A.F. conception, design, interpretation of data and manuscript preparation.

\section{Competing Interests}

All authors declare no conflict of interest.

\section{REFERENCES}

1. Castiglioni S, Maier JAM. Magnesium and cancer: a dangerous liason. Magnes. Res. 2011; 24:S92-100.

2. Wolf FI, Trapani V, Cittadini A. Magnesium and the control of cell proliferation: looking for a needle in a haystack. Magnes. Res. 2008; 21:83-91.

3. Wolf FI, Cittadini ARM, Maier JAM. Magnesium and tumors: ally or foe? Cancer Treat. Rev. 2009; 35:378-82.

4. Penner $\mathrm{R}$, Fleig $\mathrm{A}$. The $\mathrm{Mg}^{2+}$ and $\mathrm{Mg}^{(2+)}$-nucleotideregulated channel-kinase TRPM7. Handb Exp Pharmacol. 2007; 313-28.

5. Schlingmann KP, Waldegger S, Konrad M, Chubanov V, Gudermann T. TRPM6 and TRPM7--Gatekeepers of human magnesium metabolism. Biochim Biophys Acta. 2007; 1772:813-21.

6. Van der Wijst J, Hoenderop JGJ, Bindels RJM. Epithelial $\mathrm{Mg}^{2+}$ channel TRPM6: insight into the molecular regulation. Magnes Res. 2009; 22:127-32.

7. Nadler MJ, Hermosura MC, Inabe K, Perraud AL, Zhu Q, Stokes AJ, Kurosaki T, Kinet JP, Penner R, Scharenberg AM, Fleig A. LTRPC7 is a Mg.ATP-regulated divalent cation channel required for cell viability. Nature. 2001; 411:590-5.

8. Runnels LW. TRPM6 and TRPM7: A Mul-TRP-PLIKcation of channel functions. Curr Pharm Biotechnol. 2011; $12: 42-53$.

9. Li M, Jiang J, Yue L. Functional characterization of homo- and heteromeric channel kinases TRPM6 and TRPM7. J Gen Physiol. 2006; 127:525-37.

10. Monteilh-Zoller MK, Hermosura MC, Nadler MJ, Scharenberg AM, Penner R, Fleig A. TRPM7 provides an ion channel mechanism for cellular entry of trace metal ions. J Gen Physiol. 2003; 121:49-60.

11. Xie J, Sun B, Du J, Yang W, Chen H-C, Overton JD, Runnels LW, Yue L. Phosphatidylinositol 4,5-bisphosphate (PIP2) controls magnesium gatekeeper TRPM6 activity. Sci. Rep. 2011; 1:146.

12. Runnels LW, Yue L, Clapham DE. The TRPM7 channel is inactivated by PIP2 hydrolysis. Nat. Cell Biol. 2002; 4:329-36.

13. Zierler S, Yao G, Zhang Z, Kuo WC, Porzgen P, Penner R, Horgen FD, Fleig A. Waixenicin A inhibits cell proliferation through magnesium-dependent block of transient receptor potential melastatin 7 (TRPM7) channels. J. Biol. Chem. 2011; 286:39328-35.

14. Zhang Z, Yu H, Huang J, Faouzi M, Schmitz C, Penner R, Fleig A. The TRPM6 kinase domain determines the $\mathrm{Mg} \cdot \mathrm{ATP}$ sensitivity of TRPM7/M6 heteromeric ion channels. J. Biol. Chem. 2014; 289:5217-27.

15. Yu H, Zhang Z, Lis A, Penner R, Fleig A. TRPM7 is regulated by halides through its kinase domain. Cell. Mol. Life Sci. 2013; 70:2757-71.

16. Bates-Withers C, Sah R, Clapham DE. TRPM7, the $\mathrm{Mg}^{2+}$ inhibited channel and kinase. Adv. Exp. Med. Biol. 2011; 704:173-83.

17. Schmitz C, Perraud A-L, Johnson CO, Inabe K, Smith MK, Penner R, Kurosaki T, Fleig A, Scharenberg AM. Regulation of vertebrate cellular $\mathrm{Mg}^{2+}$ homeostasis by TRPM7. Cell. 2003; 114:191-200.

18. Ryazanova LV, Rondon LJ, Zierler S, Hu Z, Galli J, Yamaguchi TP, Mazur A, Fleig A, Ryazanov AG. TRPM7 is essential for $\mathrm{Mg}^{2+}$ homeostasis in mammals. Nat. Commun. 2010; 1:109.

19. Schlingmann KP, Weber S, Peters M, Niemann Nejsum L, Vitzthum H, Klingel K, Kratz M, Haddad E, Ristoff E, Dinour D, Syrrou M, Nielsen S, Sassen M, et al. Hypomagnesemia with secondary hypocalcemia is caused by mutations in TRPM6, a new member of the TRPM gene family. Nat Genet. 2002; 31:166-70.

20. Walder RY, Landau D, Meyer P, Shalev H, Tsolia M, Borochowitz Z, Boettger MB, Beck GE, Englehardt RK, Carmi R, Sheffield VC. Mutation of TRPM6 causes familial hypomagnesemia with secondary hypocalcemia. Nat Genet. 2002; 31:171-4.

21. Maris JM. Recent advances in neuroblastoma. N. Engl. J. Med. 2010; 362:2202-11.

22. Maris JM, Hogarty MD, Bagatell R, Cohn SL. Neuroblastoma. Lancet. 2007; 369:2106-20.

23. Brodeur GM. Neuroblastoma: biological insights into a clinical enigma. Nat. Rev. Cancer. 2003; 3:203-16.

24. Brodeur GM, Seeger RC, Schwab M, Varmus HE, 
Bishop JM. Amplification of N-myc in untreated human neuroblastomas correlates with advanced disease stage. Science. 1984; 224:1121-4.

25. Seeger RC, Brodeur GM, Sather H, Dalton A, Siegel SE, Wong KY, Hammond D. Association of multiple copies of the N-myc oncogene with rapid progression of neuroblastomas. N. Engl. J. Med. 1985; 313:1111-6.

26. Schwab M, Varmus HE, Bishop JM, Grzeschik KH, Naylor SL, Sakaguchi AY, Brodeur G, Trent J. Chromosome localization in normal human cells and neuroblastomas of a gene related to c-myc. Nature. 1984; 308:288-91.

27. Grimmer MR, Weiss WA. Childhood tumors of the nervous system as disorders of normal development. Curr. Opin. Pediatr. 2006; 18:634-8.

28. Boon K, Caron HN, van Asperen R, Valentijn L, Hermus MC, van Sluis P, Roobeek I, Weis I, Voûte PA, Schwab M, Versteeg R. N-myc enhances the expression of a large set of genes functioning in ribosome biogenesis and protein synthesis. EMBO J. 2001; 20:1383-93.

29. Kocak H, Ackermann S, Hero B, Kahlert Y, Oberthuer A, Juraeva D, Roels F, Theissen J, Westermann F, Deubzer H, Ehemann V, Brors B, Odenthal M, et al. Hox-C9 activates the intrinsic pathway of apoptosis and is associated with spontaneous regression in neuroblastoma. Cell Death Dis. 2013; 4:e586.

30. Lutz W, Stöhr M, Schürmann J, Wenzel A, Löhr A, Schwab M. Conditional expression of N-myc in human neuroblastoma cells increases expression of alphaprothymosin and ornithine decarboxylase and accelerates progression into S-phase early after mitogenic stimulation of quiescent cells. Oncogene. 1996; 13:803-12.

31. Mandt T, Song Y, Scharenberg AM, Sahni J. SLC41A1 $\mathrm{Mg}^{2+}$ transport is regulated via $\mathrm{Mg}^{2+}$-dependent endosomal recycling through its $\mathrm{N}$-terminal cytoplasmic domain. Biochem. J. 2011; 439:129-39.

32. Schmitz C, Dorovkov MV, Zhao X, Davenport BJ, Ryazanov AG, Perraud AL. The channel kinases TRPM6 and TRPM7 are functionally nonredundant. J Biol Chem. 2005; 280:37763-71.

33. Dorovkov MV, Ryazanov AG. Phosphorylation of annexin I by TRPM7 channel-kinase. J. Biol. Chem. 2004; 279:50643-6.

34. Clark K, Middelbeek J, Lasonder E, Dulyaninova NG, Morrice NA, Ryazanov AG, Bresnick AR, Figdor CG, van Leeuwen FN. TRPM7 regulates myosin IIA filament stability and protein localization by heavy chain phosphorylation. J. Mol. Biol. 2008; 378:790-803.

35. Prakriya M. The molecular physiology of CRAC channels. Immunol. Rev. 2009; 231:88-98.

36. Den Dekker E, Hoenderop JGJ, Nilius B, Bindels RJM. The epithelial calcium channels, TRPV5 \& TRPV6: from identification towards regulation. Cell Calcium. 2003; 33:497-507.

37. Jiang J, Li MH, Inoue K, Chu XP, Seeds J, Xiong ZG.
Transient receptor potential melastatin 7-like current in human head and neck carcinoma cells: role in cell proliferation. Cancer Res. 2007; 67:10929-38.

38. Zhang Z, Wang M, Fan X-H, Chen J-H, Guan Y-Y, Tang Y-B. Upregulation of TRPM7 channels by angiotensin II triggers phenotypic switching of vascular smooth muscle cells of ascending aorta. Circ. Res. 2012; 111:1137-46.

39. Du J, Xie J, Zhang Z, Tsujikawa H, Fusco D, Silverman D, Liang B, Yue L. TRPM7-mediated $\mathrm{Ca}^{2+}$ signals confer fibrogenesis in human atrial fibrillation. Circ. Res. 2010; 106:992-1003.

40. Sun Y, Selvaraj S, Varma A, Derry S, Sahmoun AE, Singh BB. Increase in serum $\mathrm{Ca}^{2+} / \mathrm{Mg}^{2+}$ ratio promotes proliferation of prostate cancer cells by activating TRPM7 channels. J. Biol. Chem. 2013; 288:255-63.

41. Kolisek M, Launay P, Beck A, Sponder G, Serafini N, Brenkus M, Froschauer EM, Martens H, Fleig A, Schweigel M. SLC41A1 is a novel mammalian $\mathrm{Mg}^{2+}$ carrier. J. Biol. Chem. 2008; 283:16235-47.

42. Sahni J, Scharenberg AM. TRPM7 ion channels are required for sustained phosphoinositide 3-kinase signaling in lymphocytes. Cell Metab. 2008; 8:84-93.

43. Duijkers FAM, Gaal J, Meijerink JPP, Admiraal P, Pieters R, de Krijger RR, van Noesel MM. Anaplastic lymphoma kinase (ALK) inhibitor response in neuroblastoma is highly correlated with ALK mutation status, ALK mRNA and protein levels. Cell. Oncol. 2011; 34:409-17. 